combination, and gave the barium test for glycuronic acid. It differs from chondroitin sulphuric acid in its behavior towards orcin-hydrochloric acid. It has been given the name of glucothionic acid and it is possible that the substance is not unlike the glucosaminic acid described by Fischer, combined with sulphuric acid.

F. P. UNDERHILL.

On the Biological Relation of Proteids and Proteid Assimilation. By P. A. Levene And L. B. Stookey. Am.J. Physiol., 8, XXIII. - In applying the precipitin test, the authors observed that different proteids of a given animal, and perhaps of a given species, possess a certain similarity which distinguishes them from all the proteids of any other origin. This biological individuality of proteids could serve to explain the cause of the fact that proteid material ingested has to be broken up by the organism before it is utilized. The molecule of foreign proteid material has to be reconstructed into the molecule characteristic of the given animal. An attempt was also made to determine the place of the breaking-down of the ingested proteid, and application of the precipitin test was made. This part of the work is not yet complete.

F. P. UNDERHILL.

On the Digestion of Gelatin. By P. A. LEVENE AND L. B. Stookey. Am. J. Physiol., 8, XXIII.-In order to gain some light upon the process of transformation of gelatin into gelatoses, the authors investigated the formation of free ammonia in the course of tryptic digestion of gelatin, and observed that the free ammonia increases as the gelatin is transformed into the primary, and the primary into the secondary gelatoses. F. P. UNDERHILI.

\title{
INDUSTRIAL CHEMISTRY.
}

Purity of So-called Standard Drugs and Chemicals. $\mathrm{BY}$ Virgil Coblentz. J. Soc. Chem. Ind., December I5, 1902.Professor Coblentz, in his address as chairman of the New York Section of the Society of Chemical Industry, reviews the results of himself and others in the examination of some of the wellknown drugs and chemicals as now found in the American market. Hydrochloric, sulphuric and nitric acids sold as either "C. P." or "U. S. P.," he finds to be of a high degree of purity, practically all of them standing the Berzelius-Marsh test for arsenic for at least fifteen minutes. The commercial acids are excellent also so far as the presence of arsenic is concerned, although they contain metallic impurities. Boric acid is frequently found mixed with as much as three times its weight of powdered borax. Some lots also contained calcium sulphate and calcium borate. Chromium trioxide is found almost invariably with adhering sulphuric acid amounting, in cases reported, to 5 per cent., and all samples examined by Coblentz were found to 
contain more or less alkali acid sulphate. Citric acid.-Most, if not all the samples offered, contained iron and lead, although the quality has improved in recent years. Oxalic acid has been found on the market mixed with the cheaper magnesium sulphate, one case reported containing as much as 80 per cent. of this salt. Salicylic acid has been met with, adulterated with starch and calcium sulphate. It is rarely chemically pure. Tannic acid is found extensively adulterated with such substances as dextrin, sugar, flour, salt, etc. The author found samples yielding varying quantities of ash up to 15 per cent. and the presence of dextrin was of very frequent occurrence. Acetic ether rarely conforms to the standard requirements of 98.5 per cent. Most samples vary from 30 to 60 per cent. A sample sold as "absolute" was reported as containing 86 per cent. of the pure ether. Ammonium chloride.-The powdered salt contains frequently considerable quantities of porvdered ammonia alum, also clay has been found in various samples. Antimony sulphide (native).This is extensively adulterated with chalk, sand, clay, and the like, colored with charcoal. Antipyrin.-This is frequently substituted by dispensers with the cheap and dangerous antipyretic acetanilide. Aristol. - This most valuable and popular antiseptic of recent years is very largely adulterated, either desiguedly or as the result of efforts to make the dithymol-diiodide, which is then collected and dried without washing or purifying, so that excess of alkali and free iodine are found to be present, although gross adulterants like starch, talc, calcium carbonate, zinc oxide, tripoli and boric oxide have been found in some cases. Borax.-Powdered borax, particularly that offered in package form, is extensively adulterated and even entirely substituted by sodiun bicarbonate. Even bulk goods have been found to contain, 6,38 , 44 , and 60 per cent. of pure borax, the balance consisting of soda. Bismuth salts. - All contain more or less traces of copper, arsenic, and iron, with occasionally lead and tellurium. Bromine.-Reports show that the American article contains 3.4 to 5.2 per cent. of chlorine, while the German contains but 0.53 to 0.68 per cent. Naturally all American-made bromides contain large amounts of chlorides. Calcium carbonate (precipitated). - Samples containing as much as 50 per cent. of magnesium carbonate have been reported. Calcium phosphate (precipitated).-This is frequently adulterated with powdered chalk, gypsum, or talc to the extent of 30 per cent. Creosote (Beechwood). - The majority of commercial wood creosotes are reported to consist either of low- or highboiling products with little or no guaiacol, the most valuable component. The use of impure phenol as a substitute for wood tar creosote under the name of "coal tar creosote" is also noted. A Massachusetts analyst reports that 40 per cent. of the samples sold as creosote are impure phenol. Glycerin.-Iatigmuir, in I 899 , and Patch, in I 897 , had reported that all samples of "C. P."' 
glycerin, either foreign or domestic, respond to the tests for arsenic. Coblentz found that one sample of American manufacture contained about I part of arsenious oxide to 70,000 , while another averaged I to 100,000. Hypophosphites. - These salts vary much in quality, arsenic, phosphites, and phosphates being found in nearly all samples. Iron, reduced. - This is rarely of satisfactory quality, usually containing excessive quantities of sulphide and appreciable amounts of arsenic. Moreover, the percentage of metal varies from 13 to 83 per cent., both ferrous oxide and ferric oxide being found to be present. Lead oxide (litharge).--Lead carbonate to the extent of 20 per cent. and silicious matter colored with ferric oxide and ochre have been found. Potassium hydroxide. - Recent analysis shows the percentage of hydroxide to vary from 88.5 to go with I to 3 per cent. of sodium hydroxide and but little more than traces of carbonate. The best qualities of lump potash, purchased in drums, were found to average about 86 per cent. of pure hydroxide. Potassium bromide. - As mentioned under bromine, the American bromides all contain chloride varying from 4.5 to 9 per cent. Potassium chlorate. - The admixture of pulverized alum with pulverized chlorate is of very common occurrence. Potassium bitartrate (cream of tartar). - While this chemical is easily obtained of a high degree of purity, it is still extensively sophisticated. Mixtures of alum, bitartrate and calcium phosphate and of ammonia alum and bitartrate will not show the true strength of bitartrate by cold titration, but if ignited and the ash titrated with a normal acid, after having been extracted with water and filtered, the adulteration is shown. Potassium iodide. - This chemical rarely conforms to the standard of 99.5 per cent. purity demanded by the U. S. P. As much as 8 per cent. of chloride has been found, as well as excess in alkalinity at times. Iodate is to be found in nearly all the samples of iodide. Phenacetzn.-This most popular antipyretic is quite extensively substituted by the cheap and dangerous acetanilide or mixtures of this with sugar or sodium bicarbonate. Phosphorus. - Arsenic has been found in all samples examined, even as high as I per cent. It is reported that the phosphorts made by the electric furnace, however, is free from this dangerous contamination. Sodium phosphate.-Examination of both English and American manufacture has shown the presence of arsenic, in the former case, in dangerous quantities. Sulphonal. - This extensively used hypnotic is often substituted by sodium bicarbonate or a mixture of this with acetanilide which is a dangerous substitute, considering the large doses in which sulphonal is administered. Salophen.-This is frequently found substituted by a mixture of acetanilide and sodium salicylate, the action of which is quite different. Tartar Emetic.-This contains amounts of arsenic varying from traces to appreciable quantities. 40 to 70 per cent. of potassium sulphate was found in five sam- 
ples purchased from English wholesalers. Thymol.-The high price of this antiseptic has led to sophistication with borax crystals and paraffin cut into pieces to imitate the thymol crystals. Vanillin.-This relatively expensive chemical has been found admixed with acetanilide to the extent of 50 per cent. Benzoic acid has also been found as an adulterant. The writer enters a strong plea for a National Pure Food and Drug Law, such as was introduced into Congress under the name of the Hepburn bill.

S. P. SADTLER.

Process for Rendering Phosphoric Acid Available. By Chariess Baskervilie, Ph.D. J. Soc. Chem. Ind., December 3I, I902. - The author, after endeavoring to secure a mechanical method for concentrating the phosphatic pebble of North Carolina, but without satisfactory results, tried the method of fusing the ground material with alkaline sulphates, sulphides, nitrates, and carbonates. Jigged material which contained 35 to 44 per cent. of tricalcium phosphate was taken. The use of nitrates gave the largest percentage of citrate-soluble phosphoric acid, but the expensive nitrogen was driven off. So carbonate was taken. The pulverized material in the proportion of one of carbonate to four of the crude phosphate rock, was subjected to a good red heat until there was slight sintering but no fusion. The product is easily removed from the furnace in a porous condition somewhat like pumice stone and readily ground. It does not attract moisture. From 75 to 90 per cent. of the phosphoric acid was rendered available, depending upon temperature and upon the duration of the time of heating. The percentage of rater-soluble phosphate was not notably increased.

S. P. SADTLI:R.

Antiseptics and Their Use in the Preservation of Food. By SAMUEL S. PrescotT. Tech. Quart., December, 1902.-The author in an address before the Atlantic States and Western Canned Food Associations speaks first of the nature of the changes which bring about the fermentation, putrefaction and decay of foods and then of the methods of food conservation which are grouped under four heads : Cold storage; preserving, pickling and drying; canning; and the use of antiseptics. The conditions of application of each of these methods are then detailed and the degree of protection against change stated. Of these several methods, the author indicates the greatest value to attach to canning, as this cau be combined with such a heating as to effectually sterilize the material and allow of its indefinite protection. In speaking of antiseptics or preservatives, the writer states that the number of such substances in common use for foods is relatively small. From authoritative analyses of 67 preservatives, it was found that 33 contained either borax or boric acid as the most active constituent, Io contained sulphites, 8 salicylic acid or its sodium salt, and 7 benzoic acid or its sodium com- 
pound. All of the preservatives commonly used can be easily detected by the skilled chemist, despite statements sometimes made to the contrary. The author gives a review of the recent testimony of medical authorities as to the poisonous or non-poisonous character of some of these preservatives such as boric acid for instance and finds it so conflicting as to leave the question at present undetermined. The report of the committee recently appointed by the British Government to investigate the use of preservatives in foods is, on the whole, unfavorable to the use of preservatives. S. P. SADTLER.

\section{Estimates of the Sugar Crop of the World for 1902-1903.} U. S. Consular Report, January, 1903.-

I. From the sugar beet :

\begin{tabular}{|c|c|c|c|c|c|}
\hline Gern & $\begin{array}{l}\text { I902-I903. } \\
\text { Tons. } \\
\text { I, } 950,000\end{array}$ & $\begin{array}{l}1901-1902 \text {. } \\
2,299,408\end{array}$ & $\begin{array}{l}1900-1901 . \\
I, 984, I 86\end{array}$ & $\begin{array}{c}1899-1900 \\
1,798,63 I\end{array}$ & $\begin{array}{l}1898-1899 . \\
\text { I, 72 I,7 } 18\end{array}$ \\
\hline & $1,025,000$ & $1,302,038$ & $I, 094,043$ & $1,108, \infty 07$ & $I, 051,290$ \\
\hline Fr: & $880, \infty 00$ & $1,183,420$ & $1,170,3$ & 977,580 & \\
\hline$\ldots \ldots \ldots \ldots$ & $1,275,000$ & $1,110, \infty \infty$ & 918 & & 776 \\
\hline$\ldots \ldots \ldots \ldots$ & $240, \infty 00$ & 300,000 & & & 244,017 \\
\hline & I 25,000 & & & & 763 \\
\hline Ot & $355, \infty 00$ & 400,000 & 367,919 & 263,919 & \\
\hline 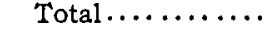 & & & $6,046,518$ & $5,518,048$ & 4,902 \\
\hline
\end{tabular}

II. From the sugar-cane :

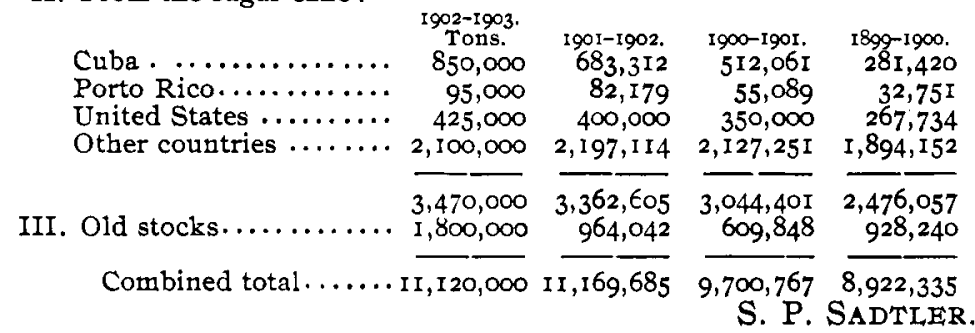

\section{AGRICULTURAL CHEMISTRY.}

Fruits and Fruit Products. By L. S. Munson, L. M. Tolman, ANd B. J. Howard. U. S. Dept. Agr., Bureau of Chem. Bull. No. 66, pp. I I4. - The primary object of the extended investigations reported in this bulletin was to determine the character of the fruit products on the market. The attempt was made to secure a thoroughly representative collection and to this end samples of all grades of jams, jellies, and similar preparations on sale at selected stores in the cities of Washington, New York, Philadelphia, and New Orleans were obtained. For purposes of comparison, numerous additional analyses were made of fresh fruits, fruit juices, and jellies and jams made in the laboratory. The bulletin was prepared under the direction of W. D. Bigelow, chief of the food laboratory. 